Keio J. Med. 19: 21-26, 1970

\title{
THE RAT PANCREATIC LIPASE ACTIVITIES FOR TRIGLYCERIDE HYDROLYSIS
}

\author{
YASUMASA MAJIMA \\ Institute of Nutrition, School of Medicine, Keio University, \\ Tokyo, Japan
}

(Received for publication March 5, 1970)

\section{INTRODUCTION}

The partial exchange of the fatty acids of triglycerides induced by the pancreatic lipase of the small intestine has not yet been explained. Borgström and Mattson studies demonstrated exchanges taking place at the 1 and 3 positions of the triglyceride and their hypothesis is the most widely accepted one at present.

Borgström et $a l^{1,2}$ studied the changes in synthesis caused by various combinations of glycerides and labelled fatty acids as well as the changes in radioisotope activities of glycerides due to the hydrolysis of triglycerides with labelled decanoic acid at the 1 and 3 positions. Mattson et al $b^{3,4}$ conducted experiments concerning the changes in iodine values of glycerides obtained by hydrolysis of various triglycerides having oleic, stearic, and palmitic acids at the 1,2 and 3 positions. However, to use the synthesis of glycerides or change in iodine number value is not a good method since hydrolysis might be different between medium and long chain fatty acids. Although they mainly used silicic acid chromatography for the separation of monoglycerides, free fatty acids might be mixed with monoglycerides in this method. Combined use of silicic acid and alumina could ensure more accurate separation.

In the present study, pancreatic lipase was made to act in vitro on triglycerides containing ${ }^{14} \mathrm{C}$-labelled oleic and palmitic acids and the monoglycerides produced were separated by silicic acid and alumina chromatography. The radioisotope activity was measured and compared with unhydrolyzed triglycerides.

Results indicated that partial exchange of long chain triglycerides did not take place at the 1 or 3 position but preferentially at the position of the 
unsaturated fatty acid. It was also found that there were 2 kinds of rat pancreatic lipase.

\section{EXPERIMENT}

\section{Materials}

a. Synthesis of triglycerides

Tripalmitin or triolein-In quinoline and chloroform, ${ }^{14} \mathrm{C}$-palmitoyl chloride or ${ }^{1-14} \mathrm{C}$-oleic acid chloride were added to $\alpha$-monopalmitin or $\alpha$-monoolein. The synthesized substances were extracted with ethanol-ether $(1: 1)$, washed with acid and water, and purified through silicic acid chromatography and then with alumina by the author's method. 5 Palmitoyl chloride or oleic acid chloride was then added to $\alpha$-mono-1-14 $\mathrm{C}$-palmitin or $\alpha$-mono-1-14 $\mathrm{C}$-olein and purification was carried out described the above.

1-palmito-2.3 diolein-To $\alpha$-monopalmitin or $\alpha$-mono-1-14C-palmitin was added ${ }^{1-14} \mathrm{C}$-oleic acid chloride or oleic acid chloride and purification was carried out as described before.

2-palmito-1.3 diolein-To $\beta$-monopalmitin or $\beta$-mono-1-14C-palmitin was added ${ }^{-14} \mathrm{C}$-oleic acid chloride or oleic acid chloride and purification was carried out as described the above.

1-oleo-2.3 dipalmitin-To $\alpha$-monoolein or $\alpha$-mono-1-14 C-olein was added 1 ${ }^{14} \mathrm{C}$-palmitic acid chloride or palmitic acid chloride and purification was carried out as described the above.

2-oleo-1.3 dipalmitin-To $\beta$-monoolein or $\beta$-mono-1-14 $\mathrm{C}$-olein ${ }^{1-14} \mathrm{C}$ palmitic acid chloride or palmitic acid chloride was added and purification was carried out as described above. Monoglycerides used in the synthesis of triglyceride were synthesized by the following method.

$\alpha$-mono-1-14 C-palmitin or $\alpha$-mono-1-14 C olein-To $\alpha$-monochlorohydrin was added ${ }^{1-14} \mathrm{C}$ palmitic acid sodium salt or $1^{-14} \mathrm{C}$ oleic acid sodium salt and water and the mixture was heated for 30 minutes at $120-130^{\circ} \mathrm{C}$. After separation with saline, and washing with ether, purification was carried out through chromatography with silicic acid followed by alumina by the author's method.5

$\beta$-mono-1-14 C-palmitin or $\beta$-mono-1-14 C olein-According to the method of Daubert ${ }^{6} \alpha, \alpha^{\prime}$-ditritylglycerine was prepared with glycerol and trtiyl (triphenyl

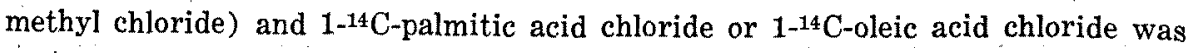
added to produce ditritylglycerine $\beta$-monopalmitin or ditritylglycerin $\beta$-monoolein.

Hydrogen was added for detritylation at $60^{\circ} \mathrm{C}$ under 3 atmospheres pressure. After extraction with ether, the mixture was washed with weak acid and water 
and purification was carried out as described above. Confirmation was carried out through infrared analysis.

To $1^{14} \mathrm{C}$-palmitic acid chloride or $1^{1-14} \mathrm{C}$ oleic acid chloride-Palmitic acid or oleic acid sodium salt was added oxalyl chloride. ${ }^{7}$ The product was extracted with benzene.

b. Chylification of trigleerides

Chylification was carried out with Fiore Nord method. ${ }^{8}$ Ten $\mathrm{ml}$ of polyvinylalcohol $(\mathrm{pH} 8.2)$ and $0.5-1.8 \mathrm{~g}$ of triglyceride were mixed in a mixer $(17,000$ rpm) for 2 minutes.

c. Extraction of rat pancreatic lipase

Pancreases obtained from adult albino rats were ground well, washed with acetone, then by acetone-ether $(1: 1)$ and finally by ether alone. After drying in a dessicator, the sample was pulverized. Glycerol was added and thoroughly mixed, the mixture was kept at $37^{\circ} \mathrm{C}$ for 4 hours and centrifuged at $3,000 \mathrm{rpm}$. The supernatant was used in the experiment.

\section{Methods}

Hydrolysis of triglycerides in vitro-Five $\mathrm{ml}$ of chylified triglyceride solution were mixed with $1.0 \mathrm{ml}$ of $0.06 \mathrm{M}$ phosphate buffer $\mathrm{pH} 8.2$ and $5.0 \mathrm{ml}$ of $\mathrm{H}_{2} \mathrm{O}$. To this mixture was added $2.0 \mathrm{ml}$ of the glycerol extract of rat pancreatic lipase described above as the enzyme. After incubating these mixtures at $37^{\circ} \mathrm{C}$ for 30 minutes, the fat was extracted using warm methanol-ether $(3: 1)$. Monoglycerides were separated according to the author's method ${ }^{5}$ and separated through chromatography with silicic acid followed by alumina. The radioisotope activity was measured using a gas G.M. Counter.

\section{RESULTS AND DISCUSSION}

1. As a preliminary experiment, various conditions of enzymatic hydrolysis in vitro were studied. Results showed that better chylification of the substrate triglyceride occurred when polyvinyl alcohol (pH8.2) was used instead of glycollic acid. The pancreatic lipase activity of the glycerol extract was higher than that of the powder. Incubation from 30-120 minutes at $\mathrm{pH} 8.2$ gave the largest production of the monoglyceride. The content of monoglyceride and free fatty acid in the substrate triglyceride were both less than $1 \%$.

2. Rat pancreatic lipase acted upon the chylified preparation of various triglycerides in vitro and the monoglycerides produced (in the state before translation of position) were separated. The radioisotope activity of this 
substance was then determined and compared with the unhydrolyzed triglyceride as shown in Table 1.

Table 1

Hydrolysis of triglycerides by rat pancreatic lipase in vitro

\begin{tabular}{c|l|c|c|c|c}
\hline $\begin{array}{c}\text { Experi- } \\
\text { ment } \\
\text { No. }\end{array}$ & \multicolumn{2}{|c|}{ Triglyceride of substrate } & \multicolumn{2}{c}{$\begin{array}{c}\text { Monoglyceride produced } \\
\text { by hydrolysis }\end{array}$} \\
\cline { 2 - 6 } Kind & $\begin{array}{c}\text { Position of } \\
\text { fatty acid } \\
\text { labelled with }\end{array}$ & $\begin{array}{c}\text { Radioisotope } \\
\text { activity } \\
\text { (counts } \\
\text { min/mg) }\end{array}$ & $\begin{array}{c}\text { Quantity } \\
\text { (\% of trigly- } \\
\text { ceride) }\end{array}$ & $\begin{array}{c}\text { Radioisotope } \\
\text { activity } \\
\text { (counts/ } \\
\text { min/mg) }\end{array}$ \\
\hline 1 & Triolein & 1 & 191 & 23.4 & 161 \\
2 & Triolein & 2,3 & 597 & 26.2 & 615 \\
3 & Tripalmitin & 1 & 312 & 29.8 & 252 \\
4 & Tripalmitin & 2,3 & 218 & 21.8 & 658 \\
5 & 1-palmito-2, 3-di-olein & 1 & 184 & 28.1 & 668 \\
6 & 1-palmito-2, 3-di-olein & 2,3 & 715 & 26.7 & 268 \\
7 & 1-oleo-2, 3-di-palmitin & 1 & 188 & 22.7 & 53 \\
8 & 1-oleo-2, 3-di-palmitin & 2,3 & 380 & 19.3 & 449 \\
9 & 2-palmito-1, 3-di-olein & 2 & 145 & 26.4 & 358 \\
10 & 2-palmito-1, 3-di-olein & 1,3 & 366 & 29.5 & 304 \\
11 & 2-oleo-1, 3-di-palmitin & 2 & 138 & 20.1 & 23 \\
12 & 2-oleo-1, 3-di-palmitin & 1,3 & 245 & 18.2 & 662 \\
\hline
\end{tabular}

In experiment 1 using triolein with a ${ }^{14} \mathrm{C}$ labelled fatty acid at the 1 position ( $\alpha$-position), the radioisotope activity of monoglyceride produced was only about $4 / 5$ that of the unhydrolyzed triolein. In experiment 2 using a triolein with ${ }^{14} \mathrm{C}$ labelled fatty acids at the 2 or 3 position ( $\beta, \alpha$ position), and the radioisotope activity was increased by 1.1 times. In experiments 3 and 4 using tripalmitin labelled with ${ }^{14} \mathrm{C}$ fatty acids at the 1 or 2.3 position, similar results were obtaincd. In experiments 7 and 8 using 1 oleo 2.3 -dipalmitin labelled with ${ }^{14} \mathrm{C}$ fatty acids at the 1 and 2-3 positions, similar results were again obtained.

In experiment 9 using 2 palmito-1.3 diolein labelled with ${ }^{14} \mathrm{C}$ at the 2 position, the radioisotope activity was increased about 2.4 times. In experiment 10 using 2-palmito-1.3 diolein labelled with ${ }^{14} \mathrm{C}$ fatty acids at the 1.3 position, the radioisotope activity was decreased about $80 \%$.

In experiment 5 with 1-palmito-2.3 diolein labelled with ${ }^{14} \mathrm{C}$ fatty acids at the 1 position, an increase of about 3.5 times was obtained. In experiment 6 with 1-palmito-2.3-diolein labelled with ${ }^{14} \mathrm{C}$ fatty acids at 2.3 position, the radioisotope activity was decreased by $2 / 5$. In experiment 11 with 2-oleo-1.3dipalmitin labelled with ${ }^{14} \mathrm{C}$ at fatty acid at the 2 position, the radioisotope activi- 
ty was decreased to about $1 / 5$ of the control while in experiment 12 with 2-oleo-1.3 dipalmitin labelled with ${ }^{14} \mathrm{C}$ fatty acids at the 1.3 position, an increase of about 2.7 times was demonstrated.

These results indicate that 4 compounds, triolein tripalmitin, 1-oleo-2.3dipalmitin and 2-palmito-1.3-diolein, are hydrolyzed at the 1.3 position to $\beta$ monoglycerides. However, 2 compounds, 1 palmito-2.3-diolein and 2-oleo-1.3dipalmitin were hydrolyzed at the 2 position to change into $\alpha$-monoglyceride. Consequently, this phenomenon cannot be explained by the 1.3 position theory of Borgström alone, but may be reasonably explained as follows. In long chain triglycerides, the fatty acids cannot be hydrolyzed at 2 positions simultaneously. All unsaturated triglycerides (simple triglyceride) or all satruated triglycerides (simple triglyceride) are hydrolyzed at the 1 or 3 position followed by the 3 or 1 position. In triglyceride with a mixture of unsaturated and saturated fatty acids, the position of the unsaturated fatty acid is preferentially hydrolyzed. The possibility of coexistence of the enzyme hydrolyzing a triglyceride into a diglyceride and the enzyme hydrolyzing the diglyceride into monoglyceride is present.

Triglycerides are not directly hydrolyzed into monoglycerides but rather go stepwise through the diglyceride. The marked difference in the property of triglycerides and diglycerides (chylibility etc.) also raises the possibility of two enzymes. The possibility of the presence of 2 pancreatic lipases and the possibility of a partial exchange with other fatty acid will be clarified in further studies.

\section{SUMMARY}

Six triglycerides consisting of oleic and palmitic acid labelled with ${ }^{14} \mathrm{C}$ were subjected to hydrolysis in vitro by rat pancreatic lipase and the radioisotope activity of the monoglyceride produced was determined. Comparison with unhydrolyzed triglycerides was accomplished. Results show the partial exchange of long chain triglyceride was found to take place not only at the 1.3 position, but also preferentially at the position of the unsaturated fatty acid. The possibility of the coexistence of 2 kinds of rat pancreatic lipase, one changing triglycerides to diglycerides and the other changing the diglyceride to a monoglyceride was suggested. 


\section{REFERENCES}

1. Borgström, B. (1954) The formation of new glyceride-ester bonds during digestion of glycerides in the lumen of the small intestine of the rat. Arch. Biochem. and Biophys. 49: 268.

2. Borgström, B. (1955) Randomization of glycride fatty acids during absorption from the small intestine of the ra.t J. Biol. Chem. 214: 671.

3. Mattson, F. H. and Beck, L. W. (1956) The specificity of pancreatic lipase for the primary hydroxyl groups of glycerides. J. Biol. Chem. 219: 735.

4. Savary, J. and Desnuelle, P. (1956) Sur guelques élémenst de spésificite pendant l'hydrolyse enzymatique des triglycérides. Biochem, Biophys, Atca, 21: 349 .

5. Majima, Y. and Kurihara, F. (1964) Separation and determination of fat. J. Jap. Soc. Food Nutrition 16: 469. (in Japanese)

6. Daubert, B. F. (1940) J. Am. Chem. Soc. 62: 1713.

7. Markley, K. S. (1961) Substitution of halogen for hydroxyl of the carboxyl group. Fatty Acids 2: 1127.

8. Nord, F. F. and Fiore, J. V. (1949) Lipasedetermination with the aid of polyvinyl alcohol. Arch. Biochem. 23: 473. 